\title{
Thoughts on Thinking: The Challenge of Critical Thinking
}

\author{
Gary Heisserer, PhD \\ Associate Vice President for Academic Affairs \\ Park University
}

Perhaps the most comprehensive definition of critical thinking comes from Halpern (1999); she writes:

Critical thinking refers to the use of cognitive skills or strategies that increase the probability of a desirable outcome. Critical thinking is purposeful, reasoned, and goal-directed. It is the kind of thinking involved in solving problems, formulating inferences, calculating likelihoods, and making decisions. Critical thinkers use these skills appropriately, without prompting, and usually with conscious intent, in a variety of settings. That is, they are predisposed to think critically. When we think critically, we are evaluating the outcomes of our thought processes-how good a decision is or how well a problem is solved. (p. 70)

Central to Halpern's definition is the idea that the critical thinker must have not only the necessary analytical tools but also the inclination to use them. Implicit in this argument is the reality that as educators, we must facilitate the learning of both critical thinking skills and dispositions.

Critical thinking may also involve the dialectical confrontation between two conflicting forces. The first is what we know and believe; the second is that which is different, new, or contrary to what we know or believe. Braman (1998) uses the phrase "disorienting dilemma" to describe the situation when one critically examines a wellformulated position that is directly at odds with a long held, and perhaps cherished, belief ( $p .30$ ). It is this dynamic process of exposure, exploration, and evaluation that is central to the liberal arts educator committed to the practice and to the instruction of critical

It is this dynamic process of exposure, exploration, and evaluation that is central to the liberal arts educator committed to the practice and to the instruction of critical thinking.

perspectives is a necessary but not sufficient condition of critical thinking. Hatcher and Spencer (2000) address this concern in their succinct but compelling definition. They write that critical thinking "attempts to arrive at a decision or judgment only after honestly evaluating alternatives with respect to available evidence and arguments" (p.1). This definition is particularly satisfying because it refers both to a process (the honest evaluation of alternatives) and to an advocacy-based result (a decision that is informed by the evidence and arguments).

In recent years much has been written about the emergence of new technologies that make previously unimaginable amounts of information immediately available. The existence of these electronic tools heightens the importance of critical thinking while also providing new challenges and opportunities for teaching and learning critical thinking skills. Halpern (1999), for example, writes that "the ability to judge the credibility of an information source has become an indispensable critical thinking skill that needs to be deliberately and repeatedly taught in college and earlier" (p. 71). Hatcher and Spencer (2000) discuss the "intellectual obligation" of critical thinking, its necessity in the workplace, its importance for problem solving at an individual and societal level, and its close relationship to effective writing ( $p .9)$.

It is clear that with the World Wide Web in particular and technology in general, the amount of available evidence, and its ease of access, has never been

Volume 1, Critical Thinking, 2006 
greater. Bangert-Drowns and Pyke (2001) confirm that the vast majority of students prefer the Internet to books or magazines for research purposes. From one perspective this increase in the amount of information and its ease of access should enhance our ability to think critically. Bradshaw, Bishop, Gens, Miller, and Rogers (2002) identify six particularly promising features of the Internet for helping to develop complex thinking skills: motivation, unlimited resources, global communication, collaboration, authentic problems, and hypertext environment. The very features outlined above also impose new and daunting challenges. Bradshaw et al. (2002) cite several of them: information overload, navigational disorientation, shallow thinking patterns, and the uneven quality of information. They note that the abundance of sources, coupled with the hyperlink environment, can lead to bewildered users. This abundant and interlinked environment can discourage deeper reflective study in

The "Googlelization" of more traditional research methodologies promotes easy-to-access, but dangerously unfiltered and non-critical examination of existing knowledge and opinion.

favor of high-speed surfing. The "Googlelization" of more traditional research methodologies promotes easy-to-access, but dangerously unfiltered and non-critical examination of existing knowledge and opinion.

In this context a particularly daunting task facing educators becomes how to leverage technology to help develop the skills and dispositions of critical thinking. Todd (1998) advocates a sort of creative utilitarianism.

He writes:

...the key challenge confronting schooling in the wake of the information technology revolution and the enormous volume of information it provides is empowering learners to be creative, critical, and constructive users of information. This has to be the central pedagogical transformation involving information technology. (Key challenges section, १1)

Fortunately, there is a significant body of literature documenting such "pedagogical transformations." These involve new partnerships between librarians and faculty designed to help students evaluate electronically-accessed material. Online tutorials are being developed helping Web-users to examine a site's purpose, sponsor, content, bias, and most recent revision (Lederer, 2000). Discipline-specific criticalthinking taxonomies are being developed to assist in the teaching and in the evaluation of critical thinking. Interactive media, electronic discussion forums, Weblogs, and Webquests have become commonplace in both the face-to-face and the online classrooms. The number of technology-enhanced teaching methods and programs claiming to help students think critically is itself overwhelming. These efforts reflect an explicit recognition of both the expanding importance and the increasing difficulty of developing critical thinking skills in our information age.

There also appears to be widespread recognition that critical thinking is a necessary component of authentic intellectual maturity. This sentiment is expressed by Villaume and Brahham (2002) in their discussion of the ramifications of being able to read critically:

After much discussion, we concluded that we choose to actively and thoughtfully construct meaning because we experience reading as an act that empowers us. We believe that we have the right and the responsibility as readers to ask our own questions, to make our own connections, to visualize our own images, and to formulate and reformulate our own predictions. ... In short, we choose to read actively and strategically because to do otherwise means that we must relinquish our rights as readers and submit to the meanings, beliefs, and purposes advocated by others. (Why do we teach section, ๆ2)

InSight: A Collection of Faculty Scholarship 
It is this empowering attribute that makes critical thinking so essential. Critical thinking and information technology have been inextricably linked. Our information age presents new challenges and new mandates for teaching critical thinking, while also presenting new and exciting opportunities.

Finally, it is with great pleasure that Park University and its Center for Excellence in Teaching and Learning explore these opportunities and address these challenges in this inaugural issue of InSight. Park's recognition of the importance of critical thinking is reflected by its prominence in the University's mission:

The mission of Park University, an entrepreneurial institution of learning, is to provide access to academic excellence which will prepare learners to think critically, communicate effectively, and engage in lifelong learning while serving a global community.

Park University has identified critical thinking as an essential component of the University's "literacies." These literacies (Analytical and Critical Thinking, Community and Civic Responsibility, Scientific Inquiry, Ethics and Values, and Literary and Artistic Expression) constitute those fundamental personal and professional skills and dispositions necessary in the development of women and men committed to lives of informed and engaged advocacy. These literacies are embedded in

Faculty commitment to these literacies is revealed both in their teaching methodologies and in their own personal and professional commitment to actions based on knowledge, discovery, and critical evaluation.

Park University's curriculum. Faculty commitment to these literacies is revealed both in their teaching methodologies and in their own personal and professional commitment to actions based on knowledge, discovery, and critical evaluation. The evidence of this commitment is reflected in the scholarship presented in the following pages.

\section{References}

Bangert-Drowns, R. L., \& Pyke, C. (2001). A taxonomy of student engagement with educational software: An exploration of literate thinking with electronic text. Journal of Educational Computing Research, 24, 213-234.

Bradshaw, A. C., Bishop, J. L., Gens, L. S., Miller, S. L., \& Rogers, M. A. (2002). The relationship of the World Wide Web to thinking skills. Educational Media International, 39, 275-284.

Braman, O. R. (1999). Teaching peace to adults: using critical thinking to improve conflict resolution. Adult Learning, 10(2), 30-32.
Halpern, D. F. (1999). Teaching for critical thinking: Helping college students develop the skills and dispositions of a critical thinker. New Directions for Teaching and Learning, 80, 69-74.

Hatcher, D. L., \& Spencer, L. A. (2000). Reasoning and writing: From critical thinking to composition. Boston: American Press.

Lederer, N. (2000). New form(at): Using the Web to teach research and critical thinking skills. Reference Services Review, 28(2), 130-153.

Todd, R. (1998). From net surfers to net seekers: WWW, critical literacies and learning outcomes. Teacher Librarian, 26(2), 16-21. 
Villaume, S. K., \& Brahham, E. G.

(2002). Comprehension instruction:

Beyond strategies. Reading Teacher,

$55,672-75$.

Heisserer is the Associate Vice President for Academic Affairs at Park University. Prior to coming to Park, Heisserer served as Director of Curriculum and Assessment at Baker University's School of Professional and Graduate Studies, as Senior Education Specialist for the Ewing Marion Kauffman Foundation, and as Chair of the Theatre Department at Graceland University. He received his PhD in Theatre from the University of Wisconsin-Madison.

InSight: A Collection of Faculty Scholarship 